\title{
Pharmacological, phytochemical and morphological study of three Mayan accessions of Bixa orellana L. leaves
}

\author{
Addy Leticia Zarza-García', Enrique Sauri-Duch², Denise Raddatz-Mota ${ }^{3}$, Luis Fernando Cuevas-Glory², \\ Luis Leonardo Pinzón-López ${ }^{4}$, Fernando Rivera-Cabrera ${ }^{3 *}$, José Alberto Mendoza-Espinoza ${ }^{5 *}$ \\ ${ }^{1}$ Programa del Doctorado de Ciencias de los Alimentos y Biotecnología. Tecnológico Nacional de México, Instituto Tecnológico de Mérida, \\ Universidad Autónoma del Carmen, Yucatán, México, ${ }^{2}$ Tecnológico Nacional de México, Instituto Tecnológico de Mérida, Yucatán, México, \\ ${ }^{3}$ Departamento de Ciencias de la Salud, Universidad Autónoma Metropolitana-Iztapalapa. Av. San Rafael Atlixco 186, Col. Vicentina, \\ C.P. 09340, México, ${ }^{4}$ Tecnológico Nacional de México, Instituto Tecnológico de Conkal, Manejo y Biotecnología de los Recursos Genéticos de \\ Cultivos Hortícolas Tropicales, Yucatán, México, ${ }^{5}$ Colegio de Ciencias y Humanidades, Academia de Biología Humana, Universidad Autónoma \\ de la Ciudad de México, México, D.F., Cátedra Alfredo Sánchez Marroquín
}

\section{A B S T R A C T}

\begin{abstract}
Achiote (Bixa orellana L.) is a plant native to tropical America. The seeds of this plant are often used in the food industry, but the leaves are underutilized. In the southeastern region of Mexico, the annatto leaves are used in the traditional Mayan medicine. While the dosage and the quality remain unclear, and we studied the chemical profile and biological activity of annatto leaves from three Mayan accessions. The qualitative analysis showed low presence of saponins and abundant anthraquinones. The annatto leaf extracts of accessions 2 and 3 had a higher content of total phenolic compounds and antioxidant capacity compared to accession 1 . Accession 3 showed antiinflammatory effects like indomethacin. In conclusion, the annatto leaves of accession 3 could be used to prepare phytomedicines due to its anti-inflammatory capacity. These results add medicinal and economic value to this crop, and indicate the importance of performing detailed pharmacological studies.
\end{abstract}

Keywords: Achiote; Anti-inflammatory activity; Antioxidant capacity; Phytochemical analysis; Total phenolic compounds.

\section{INTRODUCTION}

Plants are a critical therapy in many countries and are the basis for drug development efforts (Revathi and Rajeswari, 2015). Emerging countries encourage the incorporation of traditional medicine mainly through herbal preparations into the local health systems (Florence et al., 2015). In this context, the World Health Organization (WHO) has reported strategies to ensure the safety and efficacy of the herbal products (WHO, 2013). Thus, it is critical to find new treatments based on medicinal plants including those with abundant active metabolites such as alkaloids, glycosides, resins, essential oils, gums, tannins, coumarins, saponins, anthraquinones, flavonoids and phenolic compounds (Himesh et al., 2011; Revathi and Rajeswari, 2015; Sepúlveda et al., 2016).

The achiote plant (Bixa orellana L.) is native to tropical America. It is cultivated and principally marketed for the extraction of a dye from the seeds. This dye (also called annatto) contains the carotenoids bixin, norbixin and other products derived from lycopene. The main constituent is bixin, which represents approximately $80 \%$ of the carotenoids in the annatto colorant. Annatto is widely used in the pharmaceutical, cosmetic and food industries (Yolmeh et al., 2014; Taham et al., 2015). Despite the importance of the seeds of achiote plant, the leaves are underutilized. On the other hand, the annatto leaves have been used empirically in traditional Mayan medicine.

Literature analysis showed important biological activities from aqueous extracts of the leaves including antifungal activity, antibacterial, antioxidant, antiinflammatory, antidiarrheal, analgesic, anticarcinogenic, neuropharmacological, anticonvulsant and gastrointestinal effects (Shahid-ul-Islam et al., 2016). Some authors have studied the anti-inflammatory role of Bixa orellana leaves

\footnotetext{
*Corresponding author:

Fernando Rivera-Cabrera, Departamento de Ciencias de la Salud, Universidad Autónoma Metropolitana-Iztapalapa. Av. San Rafael Atlixco 186, Col. Vicentina, Z.C. 09340, México, City E-mail: ferivera2323@yahoo.com José Alberto Mendoza-Espinoza, Colegio de Ciencias y Humanidades, Academia de Biología Humana, Universidad Autónoma de la Ciudad de México. México, D.F., Cátedra Alfredo Sánchez Marroquín. E-mail: amendozaespinoza@gmail.com
}

Received: 17 October 2016; Revised: 21 January 2017; Accepted: 23 January 2017; Published Online: 30 January 2017 
on in vivo models (Yoke et al., 2011; Yusuf et al., 2014). However, it is important to highlight that not all cultivars have anti-inflammatory effects due to the biologic and climatical variations. Thus, it is important to locate and characterize cultivars with pharmacological potential.

The aim of this study was to morphologically describe three Mayan accessions of Bixa orellana Land then measure saponins, tannins, coumarins, anthraquinones, alkaloids, and total phenolic compounds in these specimens. We also measured the in vitro antioxidant capacity and the in vivo anti-inflammatory activity. Thus, this paper expands the utility of Mayan achiote cultivars beyond the dye to include the leaves.

\section{MATERIALS AND METHODS}

\section{Biological material and experimental set up}

The leaves of three accessions of Achiote (Bixa orellana L.) were harvested on September 2014 near Conkal, Yucatán, Mexico (Table 1). The accessions were numbered as 1, 2 and 3. Voucher specimens were authenticated and deposited in Germplasm Bank of Conkal's Technology Institute, Conkal, Yucatán, Mexico.

The leaves were dried in an oven at $35^{\circ} \mathrm{C}$ for 6 days until a constant weight was obtained. The dried leaves were powdered in a cyclone mill (mesh size $0.5 \mathrm{~mm}$ ) (UDY Corp., USA) individually. The samples were stored in airtight plastic containers at room temperature in the dark until further analysis.

This study comprised morphological, chemical and biological analysis. Morphological analysis was done qualitatively and quantitatively. The presence of saponins, tannins, coumarins, anthraquinones and alkaloids were determined qualitatively in the leaves. The total phenolic compounds were determined quantitatively in leaves. The antioxidant capacity was determined via 2,2 '-azino-bis(3ethylbenzothiazoline-6-sulphonic acid) radical cation (ABTS-+) and the 2,2-diphenyl-1-picrylhydrazy stable radical (DPPH) methods in leaf extract. Finally, the antiinflammatory effect of leaves was measured.

Table 1: Location of the leaves from different achiote (Bixa orellana L.) accessions

\begin{tabular}{|c|c|c|c|}
\hline $\begin{array}{l}\text { Accession } \\
\text { number }\end{array}$ & Region & GPS coordinates & $\begin{array}{l}\text { Voucher } \\
\text { number }\end{array}$ \\
\hline 1 & $\begin{array}{l}\text { Yucatán, } \\
\text { Mexico }\end{array}$ & N 21⒋606'; W 89³0.115' & LP10CAM01 \\
\hline 2 & $\begin{array}{l}\text { Yucatán, } \\
\text { Mexico }\end{array}$ & N 2104.615'; W 89³0.121' & JM10QR08 \\
\hline 3 & $\begin{array}{l}\text { Yucatán, } \\
\text { Mexico }\end{array}$ & N $21^{\circ} 04.6151^{\prime} ;$ W 89 $30.116^{\prime}$ & LP10CAM05 \\
\hline
\end{tabular}

aGermplasm Bank of Conkal's Technology Institute, Yucatán, Mexico

\section{Morphological analysis}

The morphological analyses of the three accessions of Bixa orellana were determined in samples of fresh plant collected from the sites described in Table 1. All plants were marked and referenced with a global positioning system (GPS). The quantitative and qualitative parameters were related to vegetative and leaf traits. Six quantitative traits (tree total height, first ramification height, trunk diameter, leaf blade length, leaf blade width, petiole length) as well as three qualitative traits (trunk surface, leaf base shape, central vein color) were measured on each plant of the three accessions.

A clinometer was used to measure the tree total height. The first ramification height was determined from the ground using a measuring tape. The trunk diameter of the tree was determined by measuring the circumference at $0.10 \mathrm{~m}$ above the ground using a measuring tape. The length and width of the leaves and fruits were measured using a ruler. Qualitative parameters were acquired by visual examination and by comparison with descriptors established by the International Plant Genetic Resources Institute (IPGRI, 1995) on Avocado (Persea spp.) and extrapolated to Bixa orellana.

\section{Extraction procedure and obtaining extracts}

The leaves $(10 \mathrm{~g})$ from each accession of Bixa orellana $(1,2$ and 3$)$ were extracted with a Soxhlet device $\left(\right.$ Pyrex ${ }^{\circledR}$, Sigma-Aldrich, USA) to eliminate the hydrophobic material from the samples, three consecutive extractions of $3 \mathrm{~h}$ were performed using $250 \mathrm{~mL}$ of hexane (first extraction), ethyl acetate (second extraction) and methanol (third extraction). The methanolic extracts were collected and concentrated to a final volume of $30 \mathrm{~mL}$ using a vacuum rotary evaporator (Yamato Scientific America (RE301AW), USA). All methanolic extracts were stored in amber flasks at $-70^{\circ} \mathrm{C}$.

\section{Chemical analysis of the extracts Qualitative analysis \\ Determination of saponins}

We used the technique described by Coolborn and Bolatito (2010) to determine the presence of saponins in the leaves of Bixa orellana. Each extract $(0.005 \mathrm{~g})$ was placed in a tube containing $10 \mathrm{~mL}$ of distilled water and then incubated $30 \mathrm{~min}$ in a water bath at $80^{\circ} \mathrm{C}$. Afterwards, the tube was allowed to cool at room temperature, stirred vigorously and left to stand for 15 to $20 \mathrm{~min}$. The presence of saponins was assessed by measuring the height $(\mathrm{mm})$ of the foam formed.

\section{Determination of tannins}

The Bixa orellana leaf extract (0.005 g) was dissolved in $10 \mathrm{~mL}$ of distilled water. The solution was divided into three test tubes and treated with: A gelatin solution 1\% 
$(\mathrm{w} / \mathrm{v})$ in test tube number 1 ; a gelatin-salt reagent $(1 \mathrm{~g}$ of gelatin and $10 \mathrm{~g}$ of $\mathrm{NaCl}$ dissolved in $100 \mathrm{~mL}$ of distilled water) in test tube number 2; and saline solution $(\mathrm{NaCl} 10 \%$ $(\mathrm{w} / \mathrm{v}))$ in test tube number 3 . The appearance of a white precipitate in test tubes number 1 and 2 and the absence of such precipitate in test tube number 3 indicated the presence of tannins (Coolborn and Bolatito, 2010; Aarland et al., 2015).

\section{Determination of coumarins}

Bixa orellana leaf extract $(0.005 \mathrm{~g})$ was added to $10 \mathrm{~mL}$ of distilled water in test tubes. The test tubes were covered with filter paper moistened in a caustic soda solution $\left(0.067 \mathrm{~g} \mathrm{~mL}^{-1}\right)$ and boiled. After $5 \mathrm{~min}$, the paper was removed from the tube, dried and exposed to UV-light. The blue fluorescence indicated the presence of coumarins (Coolborn and Bolatito, 2010; Aarland et al., 2015).

\section{Determination of anthraquinones}

The determination of anthraquinones was carried out with the method of thin layer chromatography. Silica gel plates $60 \mathrm{~F}_{254}(3 \times 5 \mathrm{~cm})$ were cut and an aliquot $(0.1 \mathrm{~mL})$ of each Bixa orellana leaf extract was applied. The eluent mixture consisted of dichloromethane and methanol 95:5 (v/v). Yellow or red fluorescent spots under UV-light indicated the presence of anthraquinones (Coolborn and Bolatito, 2010; Aarland et al., 2015).

\section{Determination of alkaloids}

An aliquot of $0.1 \mathrm{~mL}$ of each Bixa orellana extract was applied on silica gel plates $60 \mathrm{~F}_{254}(3 \times 5 \mathrm{~cm})$. The plates were eluted with the same mixture used for anthraquinones and imaged with the Dragendorff reagent. The formation of red-brown spots indicated the presence of alkaloids (Coolborn and Bolatito, 2010; Aarland et al., 2015).

\section{Quantitative analysis}

Determination of total phenolic compounds content Total phenolic compounds (TPC) were determined with the Folin-Ciocalteu phenol reagent using the technique described by Singlenton and Rossi (1965). A $200 \mu \mathrm{L}$ aliquot of diluted Bixa orellana leaves extract was mixed with $1 \mathrm{~mL}$ of Folin-Ciocalteu reagent previously diluted 1:10 (v/v) with water and incubated for 1 min before adding $0.8 \mathrm{~mL}$ of $7.5 \%(\mathrm{w} / \mathrm{v})$ sodium carbonate. The reaction mix was then incubated for $1 \mathrm{~h}$ at room temperature followed by absorbance measurements at $765 \mathrm{~nm}$. To determine the concentration of total phenolic compounds, a standard curve was prepared using gallic acid $\left(0-100 \mu \mathrm{g} \mathrm{mL}^{-1}\right)$ (Sigma-Aldrich, USA). The total phenolic content was reported as $\mathrm{mg}$ gallic acid equivalents per gram of dry leaf weight (mg GAE g ${ }^{-1} \mathrm{LDW}$ ).

\section{Pharmacological assays}

Determination of antioxidant capacity by the ABTS $^{+}$method

This method evaluated the free radical scavenging capacity of leaves extract of different Bixa orellana samples according to the method described by Rivero-Pérez et al. (2007). The radical was generated by reaction of $7 \mathrm{mM}$ solution of ABTS in deionized water with $2.45 \mathrm{mM} \mathrm{K}_{2} \mathrm{~S}_{2} \mathrm{O}_{8}(1: 1 \mathrm{v} / \mathrm{v})$. The solution was held in the dark at room temperature for at least $16 \mathrm{~h}$ to obtain a stable absorbance value at $734 \mathrm{~nm}$. Subsequently, 1X PBS buffer $\mathrm{pH} 7.4$ was used to adjust the absorbance of the radical solution to 0.7 (water as blank).

An aliquot of $100 \mu \mathrm{L}$ of trolox or each Bixa orellana of leaves extract was added to $1000 \mu \mathrm{L}$ of this solution. Diluted samples of each Bixa orellana leaves extracts in PBS buffer $1 \mathrm{X}, \mathrm{pH} 7.4$ were used. The antioxidant capacity (AC) was monitored via the decrease in absorbance at $734 \mathrm{~nm}$ (Beckman DU-650, UV-Vis spectrophotometer, USA). A standard curve was prepared with 0 to $20 \mu \mathrm{M}$ trolox (Sigma-Aldrich, USA). Results were expressed as trolox equivalent antioxidant capacity per gram of dry leaf weight [TEAC (mM g-1 LDW)].

\section{Determination of antioxidant capacity by the DPPH method}

The method used to test the antioxidant capacity of each Bixa orellana leaf extract was based on the evaluation of the free radical scavenging capacity of the extracts according to the method described by Brand-Williams et al. (1995) using a solution of $0.1 \mathrm{mM}$ of DPPH in methanol. An aliquot of $50 \mu \mathrm{L}$ of ascorbic acid or Bixa orellana leaf extract was added to $950 \mu \mathrm{L}$ of this solution. Diluted samples of the Bixa orellana leaf extracts in $80 \%$ aqueous methanol (v/v) were used. The antioxidant capacity was measured by the fall of the absorbance at $515 \mathrm{~nm}$ (Beckman DU-650, UV-Vis spectrophotometer, USA). The standard curve was prepared with 0 to $700 \mu \mathrm{M}$ ascorbic acid (Sigma-Aldrich, USA). Results were expressed as ascorbic acid equivalent antioxidant capacity per gram of dry leaf weight [AEAC (mM g-1 LDW)].

\section{Acute toxicity studies}

Aqueous extracts of the studied accessions (1,2 and 3) of Bixa orellana leaves were used. The toxicity was evaluated according to the growth and weight in male Wistar rats-36 male Wistar rats 21 days old (95 and $121 \mathrm{~g}$ ) were selected by random sampling technique. Animals had free access to feed and leaves extracts oral via ad libitum during 15 days and was divided into the following groups $(n=7)$ : Control group ( $500 \mathrm{~mL}$ water per group); three Bixa orellana $500-p p m$ (500 mg leaf powder L-1 in water) aqueous leaf extracts were used (accessions 1, 2 and 3) (see supporting information S3, S4, S5 and S6). 
Determination of the carrageenan-induced paw edema anti-inflammatory in vivo model

Inflammation was induced in 36, 72-day-old male Wistar rats with weights between 254 and $282 \mathrm{~g}$. Animals had free access to feed and leaves extracts oral via ad libitum during 10 days and divided into the following groups ( $\mathrm{n}=7$ ): Negative control group (500 mL water per group), positive control group (indomethacin $10 \mathrm{mg} \mathrm{kg}^{-1}$ in $500 \mathrm{~mL}$ water per group), three Bixa orellana aqueous leaf extract groups (accessions 1, 2 and 3) each containing $500 \mathrm{ppm}$ (500 mg leaf powder $\mathrm{L}^{-1}$ ). Inflammation was induced in the right paw by a sub-plantar injection of $0.1 \mathrm{~mL}$ of carrageenan $1 \%(\mathrm{w} / \mathrm{v})$ in saline solution $0.9 \%$ (w/v) (Cai et al., 2014). The change in edema was calculated according to the difference in the measured diameter between the non-swollen left paw and right paw treated with carrageenan. This study was done every $24 \mathrm{~h}$ during 10 days. The animals were provided by the Animal Center at Universidad Autónoma Metropolitana Unidad-Iztapalapa. Laboratory animals were handled according to CICUAL (Institutional Committee for the Care and Use of the Animals) based in the international and national rules established in the "Official Mexican Rule" for the care and use of the laboratory animals [NOM-062-ZOO-1999] (NOM, 1999).

\section{Statistical analysis}

Statistical analysis was carried out using NCSS software (2007, update 2009, v07.1.18). Data were compared applying one-way ANOVA followed by Tukey's multiple comparison tests. Values were considered as statistically significant at $\mathrm{P}<0.05$.

\section{RESULTS AND DISCUSSION}

\section{Morphological descriptors Vegetative traits}

Table 2 shows the parameters determined for three Bixa orellana accessions. Differences were observed among the accessions in terms of tree total height (from 2.23 to $3.10 \mathrm{~m}$ ), first ramification height (from 0.11 to $0.22 \mathrm{~m}$ ) and trunk diameter (from 0.09 to $0.45 \mathrm{~m}$ ). The trunk surface was smooth for all accessions (Table 2, see supporting information S-7).

\section{Leaf traits}

All the accessions had similar length characteristics (from 0.137 to $0.200 \mathrm{~m}$ ) and width (from 0.080 to $0.095 \mathrm{~m}$ ). The petiole length ranged from 0.034 to $0.051 \mathrm{~m}$. There were no differences in terms of leaf base shape because all accessions were truncate. Furthermore, differences in central vein color varied from green/yellow to green (Table 2).

\section{Chemical qualitative analysis}

These tests were carried out in methanolic leaf extracts of Bixa orellana to determine the presence of different chemical groups. Saponins, tannins, coumarins, anthraquinones and alkaloids likely underlie the therapeutic outcomes seen here. This qualitative evaluation represents an initial characterization. The results showed that Bixa orellana leaf extracts presented a high content of anthraquinones and low of saponins in all accessions studied. There were no tannins, coumarins or alkaloids in any of the Bixa orellana leaf extracts (see supporting information S2). However, Tamil et al. (2011), Bhatnagar et al. (2015), Sangvikar et al. (2015) and Gupta (2016) did identify tannins, coumarins and alkaloids in methanolic leaf extracts of Bixa orellana. The accessions studied here did not have these compounds.

\section{Total phenolic compounds content}

Phytochemicals are described as functional chemical compounds produce by plants (Huang et al., 2010). One of these phytochemicals are the phenolic compounds ubiquitous in all plants tissues which have an aromatic ring bearing one or more substituents (Young, 2010). Currently, these chemical compounds have attracted attention due to their activity and beneficial effects on human health (Han et al., 2007). Phenolic compounds play an important role in the coloration of plants and as defense substances against pathogens and herbivores. As well as they have been involved in essential processes of reproduction and growth (Baidez et al., 2007). Besides, Plant phenolics have been attributed a wide spectrum of pharmacological activities (Young, 2010). In vitro studies have shown that polyphenols are strong antioxidants that could complement and enhance to the function of enzymatic and non-enzymatic antioxidant systems as defense mechanism against oxidative stress caused by an imbalance in reactive oxygen species in cellular metabolic processes (Tsao, 2010).

Table 2: List of results of measured descriptors in vegetative and leaf traits of three Bixa orellana accessions

\begin{tabular}{|c|c|c|c|c|c|c|c|c|c|c|}
\hline \multirow{2}{*}{$\begin{array}{l}\text { Accession } \\
\text { number }\end{array}$} & \multirow{2}{*}{$\begin{array}{l}\text { Voucher } \\
\text { number }^{\mathrm{a}}\end{array}$} & \multicolumn{4}{|c|}{ Vegitative traits } & \multicolumn{5}{|c|}{ Leaf traits } \\
\hline & & $\begin{array}{l}\text { Tree total } \\
\text { height }(m)\end{array}$ & $\begin{array}{c}\text { First } \\
\text { ramification } \\
\text { height }(\mathrm{m})\end{array}$ & $\begin{array}{c}\text { Trunk } \\
\text { diameter }(\mathrm{m})\end{array}$ & $\begin{array}{l}\text { Trunk } \\
\text { surface }\end{array}$ & $\begin{array}{l}\text { Leaf blade } \\
\text { length }(\mathrm{m})\end{array}$ & $\begin{array}{c}\text { Leaf blade } \\
\text { width }(\mathrm{m})\end{array}$ & $\begin{array}{l}\text { Leaf base } \\
\text { shape }\end{array}$ & $\begin{array}{c}\text { Petiole } \\
\text { length }(\mathrm{m})\end{array}$ & $\begin{array}{l}\text { Central vein } \\
\text { color }\end{array}$ \\
\hline 1 & LP10CAM01 & 2.23 & 0.18 & 0.45 & Smooth & 0.137 & 0.090 & Truncate & 0.034 & Green/yellow \\
\hline 2 & JM10QR08 & 2.41 & 0.22 & 0.09 & Smooth & 0.158 & 0.095 & Truncate & 0.051 & Green/yellow \\
\hline 3 & LP10CAM05 & 3.10 & 0.11 & 0.13 & Smooth & 0.200 & 0.080 & Truncate & 0.044 & Green \\
\hline
\end{tabular}

aGermplasm Bank of Conkal's Technology Institute, Yucatán, Mexico. All measures are given as a mean. Abbreviations: m, meters 
The total phenolic compound (TPC) metric is a parameter generally determined as part of the phytochemical profile of plant tissues. The highest content of TPC was observed in the leaf extracts of accessions $2(158.77 \pm 3.75 \mathrm{mg}$ GAE g $\left.{ }^{-1} \mathrm{LDW}\right)$ and 3 (163.00 $\left.\pm 8.41 \mathrm{mg} \mathrm{GAE} \mathrm{g}^{-1} \mathrm{LDW}\right)$ in comparision with accession 1 (113.53 $\pm 7.20 \mathrm{mg} \mathrm{GAE} \mathrm{g}^{-1}$ LDW). No significant differences $(\mathrm{P}>0.05)$ were observed between accessions 2 and 3. Leaf extract of accession 1 showed 1.4-fold lower TPC in comparision with another accessions studied (Table 3).

In this work TPC in leaf extracts was 2.6-fold lower on average to those reported in other plants rich in TPC such as green tea, where up to $381 \mathrm{mg}$ gallic acid equivalents per gram of dry leaf weight (mg GAE $\mathrm{g}^{-1} \mathrm{LDW}$ ) have been reported. Fu et al. (2011) studied the TPC of 51 tea infusions and they reported that the TPC varied from 0.032 to $1.395 \pm$ g gallic acid equivalent (g GAE)/L. In this sense, the TPC levels observed in the accessions studied which varied from 113 to $163 \mathrm{mg}$ GAE g-1 LDW could be considered as a good source of phenolics (Table 3).

\section{Pharmacological analysis Antioxidant capacity}

Antioxidant capacity is a parameter generally determined as part of the phytochemical profile of plant tissues. The evaluation of the AC may be an appropriate tool to determine the additive antioxidante properties of plantderived natural products (Raddatz et al., 2016).

ABTS is an accurate method extesively used to determine the antioxidant capacity of food, primarily based on the determination of the compounds present that act as suppressors of free radicals. On the other hand, DPPH is one of the main methods used for the determination of the antioxidant capacity in hydrophilic fractions due to its sensitivity to detect active substances at low concentrations (Aarland et al., 2016).

The AC experiments using ABTS method and leaf extract samples showed that accession $2(121.67 \pm 7.31$

\begin{tabular}{|c|c|c|c|}
\hline \multirow{2}{*}{$\begin{array}{l}\text { Accession } \\
\text { number }\end{array}$} & \multicolumn{3}{|c|}{ Leaf } \\
\hline & $\begin{array}{c}\text { TPC } \\
\text { (GAE) }\end{array}$ & $\begin{array}{c}\text { AC } \\
(T E A C)\end{array}$ & $\begin{array}{c}A C \\
(A E A C)\end{array}$ \\
\hline & & ABTS & DPPH \\
\hline 1 & $113.53 \pm 7.20^{a}$ & $58.40 \pm 5.12^{a}$ & $4775.92 \pm 97.99^{a}$ \\
\hline 2 & $158.77 \pm 3.75^{b}$ & $121.67 \pm 7.31^{c}$ & $12433.64 \pm 509.96^{b}$ \\
\hline 3 & $163.00 \pm 8.41^{b}$ & $93.73 \pm 5.21^{b}$ & $11440.27 \pm 668.40^{\mathrm{b}}$ \\
\hline \multicolumn{4}{|c|}{$\begin{array}{l}\text { Values are the mean of three replicates } \pm \text { standard deviation. Same letters } \\
\text { within the same column do not differ significantly }(\mathrm{P}<0.05) \text { according } \\
\text { to Tukey's test. Abbreviations: TPC }\left(\mathrm{GAE} \mathrm{mg} \mathrm{g}^{-1} \mathrm{LDW}\right) \text {; total phenolic } \\
\left.\text { compounds. TEAC (mM g }{ }^{-1} \mathrm{LDW}\right) \text {; trolox equivalent antioxidant capacity. } \\
\left.\text { AEAC (mM g } \mathrm{g}^{-1} \mathrm{LDW}\right) \text {; ascorbic acid equivalent antioxidant capacity. } \\
\text { AC; antioxidant capacity. LDW; leaf dry weight }\end{array}$} \\
\hline
\end{tabular}

TEAC $\mathrm{mM} \mathrm{g}^{-1}$ LDW) had the highest AC followed by accession 3 (93.73 \pm 5.21 TEAC $\left.\mathrm{mM} \mathrm{g}^{-1} \mathrm{LDW}\right)$; accession 1 was the lowest (58.40 $\left.\pm 5.12 \mathrm{TEAC} \mathrm{mM} \mathrm{g}^{-1} \mathrm{LDW}\right)$ (Table 3).

The highest antioxidant capacity (AC) was observed in the leaf extracts using DPPH method were AC varied from 4775 to 12433 [AEAC (mM g-1 LDW)]. The DPPH method with leaf extracts indicated that accessions $2(12433.64 \pm 509.96$ $\left.\mathrm{AEAC} \mathrm{mMg}^{-1} \mathrm{LDW}\right)$ and $3\left(11440.27 \pm 668.40 \mathrm{AEAC}^{\mathrm{mMg}}{ }^{-1}\right.$ LDW) had a higher AC than accession 1 (4775.92 \pm 97.99 AEAC mM g-1 LDW). The DPPH results were higher than the ABTS results (Table 3). There are strong correlation between TPC content and AC in leaf extracts $[\mathrm{R} 2=0.8610$ (for ABTS); R2= 0.9807 (for DPPH)].

\section{Toxicologic and anti-inflammatory effect of Bixa orellana leaf extracts}

Leaf extracts had no toxic effects in male Wistar rats (see supporting information S3-S6). Bixa orellana leaf extracts from accessions 1, 2 and 3 all had a strong antiinflammatory effect against plantar edema in male Wistar rats- the effects were similar to indomethacin. Accession 1 reduced the inflammation on day 4 , the accession 2 on day 7 , and accession 3 on day 5 (Fig. 1). Indomethacin was effective on day 2. Accession 1 was faster than accession 3 , which offered a strong anti-inflammatory effect. The results are similar to Yusuf et al. (2014) who observed an anti-inflammatory effect of Bixa orellana leaf infusion in a model of plantar edema in Wistar rats.

Polyphenolic compounds can not only act as antioxidants, but can also have an anti-inflammatory effect as well (Eddine et al., 2016; Sepúlveda et al., 2016); however, there was poor correlation between TPC and AC and antiinflammatory effects. Accession 1 had a lower TPC and AC; however, accession 2 had a higher anti-inflammatory effect. This suggests that higher TPC and AC presented lower anti-inflammatory effects.

The anti-inflammatory activity is likely due to anthraquinones or saponins. Other authors have associated anthraquinones and saponins with anti-inflammatory activity (Odeyemi et al., 2015; Park et al., 2016). While indomethacin has a higher anti-inflammatory effect than the three other extracts, this effect may be due to higher concentrations of the drug in the pharmaceutical preparation. The dose of the whole herbal preparation was similar to the indomethacin control, and the concentration of the active substance in the herbal extracts is possibly lower.

\section{CONCLUSION}

Our results indicate that annatto leaves of accession 3 could be used to manufacture a phytomedicine with 


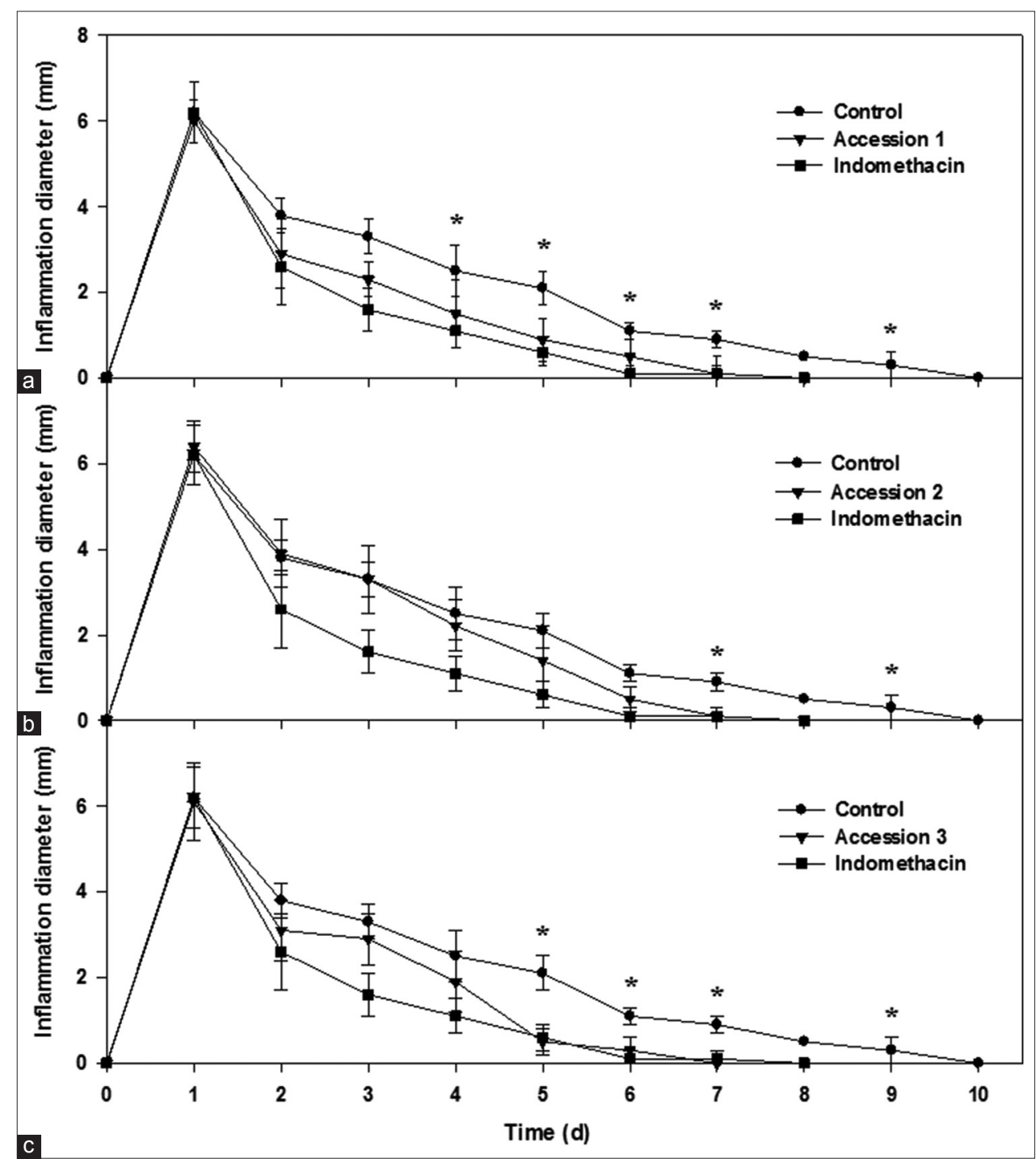

Fig 1. Anti-inflammatory effect of Bixa orellana leaf extracts (a, accession 1; b, accession 2 and c, accession 3) in the paw edema model. Abbreviations: $d$, days. *Indicates significant differences at $\alpha=0.05, n=7$.

promising anti-inflammatory capacity analogous to the positive control. This justifies the propagation of this cultivar (accession 3) in the Mayan zone in addition to use of the seeds in the food industry. Annatto leaves can be used in the pharmacological industry, but it is important to standardize the active substances in the leaves of the annatto before commercialization of annatto leaves destined or pharmaceutical applications.

\section{ACKNOWLEDGEMENTS}

This work has been partially supported by Universidad Autónoma Metropolitana-Iztapalapa, SINAREFI-RED ACHIOTE, REMEFI, Universidad Autónoma de la Ciudad de México and Instituto Tecnológico de Mérida.

\section{Declarations of conflict of interest}

The authors report no declarations of conflict of interest.

\section{Authors' contributions}

All authors of the paper contributed equally to the writing of the paper and were involved in the overall planning and supervision of the work.

\section{REFERENCES}

Aarland, R. C., S. Peralta-Gómez, C. S. Morales, F. ParraBustamante, J. M. Villa-Hernández, F. Díaz de León-Sánchez, L. J. Pérez-Flores, F. Rivera-Cabrera and J. A. Mendoza-Espinoza. 2015. A pharmacological and phytochemical study of medicinal plants used in Mexican folk medicine. Indian J. Tradit. Knowl. 4: $550-557$.

Aarland, R. C., A. E. Bañuelos-Hernández, M. Fragoso-Serrano, E. D. C. Sierra-Palacios, F. Díaz de León-Sánchez, L. J. Pérez-Flores, F. Rivera-Cabrera and J. A. Mendoza-Espinoza. 2016. Studies on phytochemical, antioxidant, anti-inflammatory, hypoglycemic and antiproliferative activities of Echinacea purpurea and Echinacea angustifolia extracts. Pharm. Biol. 55: 649-656.

Baidez, A. G., P. Gomez, J. A. Del Rio and A. Ortuno. 2007. 
Dysfunctionality of the xylem in Olea europaea L. plants associated with the infection process by Verticillium dahliae Kleb. Role of phenolic compounds in plant defense mechanism. J. Agric. Food Chem. 55: 3373-3377.

Bhatnagar, S., S. Swain and M. Sahoo. 2015. Bixa oreallana. L: A study of phytochemical, cytotoxic and antioxidant activity profile of the leaf extracts of the plant. World J. Pharm. Res. 4: $2715-2719$.

Brand-Williams, W., M. E. Cuvelier and C. Berset. 1995. Use of a free radical method to evaluate antioxidant activity. LWT Food Sci. Technol. 28: 25-30.

Cai, C., Y. Chen, S. Zhong, B. Ji, J. Wang, X. Bai and G. Shi. 2014. Anti-inflammatory activity of $n$-butanol extract from Ipomoea stolonifera in vivo and in vitro. PLoS One. 9: 1-9.

Coolborn, A. F. and B. Bolatito. 2010. Antibacterial and phytochemical evaluation of three medicinal plants. J. Nat. Prod. 3: 27-34.

Eddine, L. S., O. M. Redha and S. Ladjel. 2016. Influence of solvent extraction on phenolic content, antioxidant and anti-inflammatory activities of aerial parts extract from Algerian Artemisia Herbaalba. J. Pharm. Res. 10: 58-64.

Florence, A. R., S. Sukumaran, J. Joselin, T. S. Brintha and S. Jeeva. 2015. Phytochemical screening of selected medicinal plants of the family Lythraceae. Biosci. Discov. 6: 73-82.

Fu, L., B. T. Xu, R. Y. Gan, Y. Zhang, X. R. Xu, E. Q. Xia and H. B. Li. 2011. Total phenolic contents and antioxidant capacities of herbal and tea infusions. Int. J. Mol. Sci. 12: 2112-2124.

Gupta, P. 2016. Bixa orenalla: A review on its phytochemistry, traditional and pharmacological uses. World J. Pharm. Sci. 4: 500-510.

Han, X. Z., T. Shen and H. X. Lou. 2007. Dietary polyphenols and their biological significance. Int. J. Mol. Sci. 8: 950-988.

Himesh, S., S. Sarvesh, P. S. Sharan and K. Mishra. 2011. Preliminary phytochemical screening and HPLC analysis of flavonoid from methanolic extract of leaves of Annona squamosa. Int. Res. J. Pharm. 5: 242-246.

Huang, W. Y., Y. Z. Cai and Y. Zhang. 2010. Natural phenolic compounds from medicinal herbs and dietary plants: Potential use for cancer prevention. Nutr. Cancer. 62: 1-20.

IPGRI. 1995. Descriptors for Avocado (Persea spp.), International Plant Genetic Resources Institute, Rome, Italy.

NOM, 1999. NOM-062-ZOO. Especificaciones Técnicas para la Producción, Cuidado y Uso de los Animales de Laboratorio. Available from: http://www.fmvz.unam.mx/ fmvz/principal/ archivos/062ZOO.PDF. [Last accessed on 2016 Jul 15].

Odeyemi, S., A. Afolayan and G. Bradley. 2015. In vitro antiinflammatory and free radical scavenging activities of crude saponins extracted from Albuca bracteata jacq. bulb. Afr. J. Tradit. Complement. Altern. Med. 12: 34-40.

WHO, 2013. World Health Organization. Estrategia de la OMS Sobre Medicina Tradicional 2014-2013, Ediciones de la OMS, Hong Kong SAR, China.
Park, J. G., C. K. Seung, H. K. Yun, S. Y. Woo, K. Yong, H. Sungyoul, K. Kyung-Hee, C. Y. Byong, H. K. Sni, K. Jong-Hoon and Y. C. Jae. 2016. Anti-inflammatory and antinociceptive activities of anthraquinone-2-carboxylic acid. Mediators Inflamm. 2016: 1-12.

Raddatz-Mota, D., L. J. Pérez-Flores, F. Carrari, M. Insani, R. Asis, J. A. Mendoza-Espinoza, F. Díaz de León-Sánchez, F. RiveraCabrera. 2016. Chemical characterization and quantification of the pigment extraction yield of seven mexican accessions of Bixa orellana. Rev. Mex. Ing. Quim. 3: 727-740.

Revathi, D. and M. Rajeswari. 2015. Phytochemical analysis of Guettarda speciosa Linn. Asian J. Plant Sci. Res. 5: 1-4.

Rivero-Pérez, M. D., P. Muñiz and M. L. González-Sanjosé. 2007. Antioxidant profile of red wines evaluated by total antioxidant capacity, scavenger activity, and biomarkers of oxidative stress methodologies. J. Agric. Food Chem. 55: 5476-5483.

Sangvikar, S., M. Malgaonkar, C. Sharma, S. Kumar and S. N. Murthy. 2015. Comparative phytochemical screening of qualitative and quantitative parameters of Bixa orellana L. World J. Pharm. Pharm. Sci. 4: 1001-1017.

Sepúlveda, R. C. T., G. G. L. Ciro and M. J. E. Zapata. 2016. Extracción de compuestos fenólicos y actividad antioxidante de hojas de Bixa orellana L. (achiote). Rev. Cubana Plant Med. 21: 1-12.

Shahid-UI-Islam, L. J. Rather and M. Faqeer. 2016. Phytochemistry, biological activities and potential of annatto in natural colorant production for industrial applications-A review. J. Adv. Res. 7: 499-514.

Singlenton, V. and J. Rossi. 1965. Colorimetry of total phenolics with phosphomolyb dic-phosphotungstic acid reagents. Am. J. Enol. Vitic. 16: 144-158.

Taham, T., F. A. Cabral and M. A. S. Barrozo. 2015. Extraction of bixin from annatto seeds using combined technologies. J. Supercrit. Fluids. 100: 175-183.

Tamil, S. A., M. G. Dinesh, R. S. Satyan, B. Chandrasekaran and C. Rose. 2011. Leaf and seed extracts of Bixa orellana L. exert antimicrobial activity against bacterial pathogens. J. Appl. Pharm. Sci. 1: 116-120.

Tsao, R. 2010. Chemistry and biochemistry of dietary polyphenols. Nutrients. 2: 1231-1246.

Yoke, K. Y., A. K. Arifah, S. Sukardi, A. H. Roslida, M. N. Somchit and A. Zuraini. 2011. Bixa orellana leaf extract inhibits bradykinininduced inflammation through suppression of nitric oxide production. Med. Princ. Pract. 20: 142-146.

Yolmeh, M., M. B. Habibi-Najafi and R. Farhoosh. 2014. Optimisation of ultrasound-assisted extraction of natural pigment from annatto seeds by response surface methodology (RSM). Food Chem. 155: 319-324.

Young, C. K. 2010. Neuroprotective phenolics in medicinal plants. Arch. Pharm. Res. 33: 1611-1632.

Yusuf, S. M., E. Rohmawaty and R. Nusjirwan. 2014. Bixa orellana L. leaf infusion as an anti-inflammatory agent in aarrageenaninduced wistar rats. Aleatha Med. J. 1: 60-64. 